\title{
Packages of management control systems, entrepreneurial orientation, and performance in Brazilian startups
}

\author{
Anderson Betti Frare \\ Graduate Program in Accounting \\ Federal University of Santa Catarina \\ Florianópolis, Santa Catarina, Brazil \\ Ana Paula Capuano da Cruz \\ Department of Accounting \\ Federal University of Rio Grande \\ Rio Grande, Rio Grande do Sul, Brazil \\ Carlos Eduardo Facin Lavarda \\ Department of Accounting \\ Federal University of Santa Catarina \\ Florianópolis, Santa Catarina, Brazil

\section{Chris Akroyd} \\ Department of Accounting and Information Systems \\ University of Canterbury \\ Christchurch, New Zealand
}

\begin{abstract}
Reference
Frare, A.B., Cruz, A.P.C.d., Lavarda, C.E.F. and Akroyd, C. (2021), "Packages of management control systems, entrepreneurial orientation, and performance in Brazilian startups", Journal of Accounting \& Organizational Change, Vol. ahead-of-print No. ahead-ofprint. https://doi.org/10.1108/JAOC-04-2021-0052
\end{abstract}

\section{Available at}

https://www.emerald.com/insight/content/doi/10.1108/JAOC-04-2021-0052/full/html 


\begin{abstract}
Purpose - This study seeks to understand the relationship between the elements of a startup firms' management control system (MCS) package, its entrepreneurial orientation (EO) and firm performance.
\end{abstract}

Design/methodology/approach - We collected survey data from a sample of 100 Brazilian startups who had exited technology-based parks and incubators. We used two data analysis techniques: partial least squares structural equation modeling (PLS-SEM) and fuzzy-set qualitative comparative analysis (fsQCA).

Findings - The findings show that cultural and planning controls were the only two MCS elements that were included in all high-performing startup firms' MCS packages. We also found that EO has a positive influence on firm performance through the MCS package.

Originality - Using fsQCA and PLS-SEM we were able to better understand the important role that MCS package adoption has on a startups' performance and provide new evidence regarding the interface between MCS and EO. This extends our understanding of the importance that cultural and planning controls have in an MCS package to support startup performance.

Research implications - Our mixed-method approach allowed for a holistic view of the analyzed phenomenon. PLS-SEM analysis was applied to the symmetric relationships between the proposed relationships while fsQCA was used to analyze the asymmetric combinations between EO dimensions and MCS package elements which promoted high firm performance.

Practical implications - We show how different combinations of MCS elements form a package, mediating EO which can enable high performance.

Keywords Management control system, MCS Package, Entrepreneurial orientation, Performance, Startup, Cultural control, Planning control, Survey, fsQCA, Brazil

Paper type Research paper 


\section{Introduction}

Examining management control system (MCS) design is integral to understanding how management seeks to achieve organizational objectives and goals (Janka, 2021; Jukka and Pellinen, 2020). Adopting and using MCS in startups is an important area of research because these firms need to quickly develop these systems to help them survive in a highly competitive environment (Davila et al., 2015; Samagaio et al., 2018; Crespo et al., 2019; Pavlatos, 2021). It has been argued that MCS elements can be combined to form different packages of MCS (Otley, 1980; Malmi and Brown, 2008), which has been demonstrated to be important for entrepreneurial companies (Akroyd et al., 2019). Research has also shown that there are multiple and equally effective ways for an organization to combine MCS elements in the same strategic context. This is known as equifinality (Bedford et al., 2016) and has been argued to help improve organizational performance (Davila and Foster, 2005; Bedford, 2015; Cosenz and Noto, 2015). The MCS package ${ }^{1}$ concept has been used to understand how a number of different control system elements (cultural, planning, cybernetic, rewards \& compensation, and administrative controls) work together to enable alignment between individual activities and organizational goals (Otley, 1980; Malmi and Brown, 2008; Grabner and Moers, 2013; Bedford et al., 2016; O'Grady and Akroyd, 2016).

In this study, we contribute to this stream of research by examining the different MCS packages high-performing startups have adopted, as well as understanding the effect that the interface between a startup firm's entrepreneurial orientation (EO) and its MCS package has on startup firms' performance. A firms EO has been shown to be an important organizational attribute (Wales et al., 2020) encompassing the innovativeness, proactiveness, and risk-taking behavior of startups (Miller, 1983; Covin and Slevin, 1989). While EO has been shown to have a direct influence on firm performance (e.g., Shirokova et al., 2016; Migliori et al., 2019; Vaznyte and Andries, 2019; Basco et al., 2020; Galbreath et al., 2020), it has also been argued to affect adoption and use of MCS (Li et al., 2006; Bisbe and Malagueño, 2015; Daciê et al., 2017). This study addresses how EO and MCS influence startup performance by examining two research questions:

RQ1. Does EO influence the adoption of an MCS package and performance in startup firms?

\footnotetext{
${ }^{1}$ We use the term 'MCS package' to denote a management control system that includes "a loosely integrated set of mechanisms that operate independently" (Merchant and Otley, 2020, p. 2)
} 
RQ2. What is the relationship between combinations of EO dimensions and MCS elements in high performing startup firms?

To examine these research questions, we collected survey data from a sample of 100 Brazilian startups who exited technology-based parks and incubators, which belong to the Brazilian innovation environment, to promote cooperation and set a national movement for innovative entrepreneurship (Plonski, 2016). This entrepreneurial ecosystem enables a creative and innovative environment for startups (Latorre et al., 2017). Moreover, Technology-based parks and incubators help these companies develop their management systems (Phillips, 2002; Davila, 2019).

It has been argued that the adoption of MCS package elements differs according to the growth and maturity phases of startups. For example, startups often begin by adopting informal cultural controls and then incorporate other controls as they grow (Strauss et al., 2013; Akroyd and Kober, 2020). However, it is not yet clear which elements of the MCS package support a startup firm's performance after they exit a technology park/incubator.

Two techniques were adopted for data analysis: partial least squares structural equation modeling (PLS-SEM) is used to answer RQ1 and fuzzy-set qualitative comparative analysis (fsQCA) is used to answer RQ2. This mixed-method approach allows for a holistic view of the analyzed phenomenon through a complementary explanatory design (Johnson and Onwuegbuzie, 2004). PLS-SEM analysis was applied to the symmetric causal relationships between the proposed relationships. FsQCA was used to analyze the asymmetric causal combinations between EO dimensions and MCS package elements to promote a high level of performance. FsQCA enables us to see how different combinations of MCS elements form a package, resulting in high organizational performance, by considering the complementarity/ substitutability between MCS elements (Bedford and Sandelin, 2015; Bedford et al., 2016; Bedford, 2020) and providing new ways to identify the multidimensional profile of EO (Covin and Wales, 2019).

Our findings demonstrate that cultural and planning controls acted in a complementary way as they were the only two MCS elements that were included in all high-performing startup firms' MCS packages. We also found that EO dimensions influence the adoption of the MCS package, and also indirectly influences performance through partial MCS package mediation. Four causal combinations were found between EO interface dimensions and MCS package elements accountable for promoting high startup performance. FsQCA results complemented 
the PLS-SEM findings by exploring the aforementioned symmetrical and asymmetric relationships and reinforced the important role of MCS package adoption by startups.

This study presents a number of theoretical contributions by providing new evidence on the interface between EO dimensions and the MCS elements that comprise a package in startup firms. First, the study contributes to the MCS as a package literature, showing several paths that lead to the same outcome (equifinality) through the use of fsQCA analysis (Bedford et al., 2016; Bedford, 2020). Second, the study contributes to the literature by clarifying our understanding of the interface between the dimensions of EO and MCS elements (Li et al., 2006; Bisbe and Malagueño, 2015; Daciê et al., 2017). Third, traditionally, studies have explored contextual factors that lead to the adoption of MCS in startup firms, such as strategy (Davila et al., 2015; Samagaio et al., 2018; Crespo et al., 2019; Pavlatos, 2021; Pavlatos and Kostakis, 2021), structure (Samagaio et al., 2018; Crespo et al., 2019; Pavlatos, 2021), and environment (Samagaio et al., 2018; Pavlatos, 2021; Pavlatos and Kostakis, 2021). In this study we contribute to this line of research by identifying another organizational attribute, EO, which leads to the adoption of the MCS in startups. Furthermore, the study contributes by using the MCS package concept (Otley, 1980; Malmi and Brown, 2008), which enables us to better understand how MCS elements interact with each other to form different packages that lead to high performance of startups, based on the premise of equifinality (Bedford and Sandelin, 2015), which argues that there are many different ways that organizations can achieve success.

This study also contributes to our understanding of the practices of the managers/founders of startups by highlighting the relevance of the adoption of cultural and planning controls in an MCS package and by showing the relevance of EO, which enables startup firms to achieve higher levels of performance. Our findings can also be useful for managers of technology parks and incubators as it presents examples of the EO dimensions and MCS elements necessary to boost startup success and exit rates, which would enable them to help more startup firms. Furthermore, our findings are useful for policy makers and investors who are using managerial and financial information to evaluate startups and distribute funding.

The remainder of this paper is organized as follows. Section 2 introduces the theoretical framework and develops our hypotheses. Section 3 describes our survey methodology and measurement of the variables. Section 4 presents the data analysis. Section 5 discusses our findings and concludes the paper by highlighting our contributions, research limitations, and avenues for future research. 


\section{Theoretical framework}

\subsection{MCS package in startups}

We know that combinations of MCS “operate as a package of interrelated mechanisms" (Bedford and Malmi, 2015, p. 1) to promote information for managerial decision-making to enable goal congruence (Bedford and Sandelin, 2015). These MCS packages can include a number of MCS elements, including cultural, planning, cybernetic, rewards \& compensation, and administrative controls (Malmi and Brown, 2008). Studies on the design and use of MCS in startups are relatively recent in the literature (Davila et al., 2015; Samagaio et al., 2018; Crespo et al., 2019; Pavlatos, 2021) and to our knowledge have not used the MCS package concept.

In contrast to mature organizations, startups are formed by people gathered together to create new businesses (Davila, 2019), which can bring new ideals and technologies to the market (Bikse et al., 2018). The founders of these companies can imprint their MCS, which has been shown to have positive influence on organizational outcomes (Akroyd and Kober, 2020). However, many startups, do not survive (Cantamessa et al., 2018), as they face organizational and managerial challenges (Davila et al., 2015).

It has been argued that combinations of MCS elements can have a positive effect on an organization's performance (Davila and Foster, 2005; Cosenz and Noto, 2015; Bedford, 2015). However, studies have also demonstrated that organizational context can impact the relationship between MCS elements and organizational performance. For example, the country where the startup is based and the CEO' beliefs about planning potentially influences the use of financial MCS such as budgets, which has been argued to affect the performance of startups (Pavlatos and Kostakis, 2021). While some startups have been shown to adopt a number of formal MCS elements (Lin et al., 2017), others do not and instead rely on informal controls (Davila et al., 2015). This shows that understanding the context impacting the adoption of an MCS package is critical (Otley, 2016). Incubators and technology parks are unique ecosystems that can significantly contribute to our understanding of the adoption of MCS packages by startups (Davila, 2019). These organizations are an important factor that can have a positive effect on the adoption of an MCS package within a startup firm, which can improve their organizational performance. For this reason, we hypothesize that:

H1: The adoption of MCS packages by startup firms is positively associated with firm performance. 


\subsection{Entrepreneurial orientation}

EO is among the most studied topics in management research (Wales et al., 2011; Martens et al., 2016; Wales, 2016; Covin and Wales, 2019; Wales et al., 2019). This construct includes innovativeness, proactiveness, and risk-taking (Miller, 1983; Covin and Slevin, 1989) as organizational attributes derived from top management styles, organizational element combinations, and new entry initiatives (Wales et al., 2020). Basically, EO is "the most fundamental manifestation level of entrepreneurship as organizational attribute" (Covin and Wales, 2019, p. 4).

Previous EO literature commonly explores organizational attitudes of innovativeness, risk-taking, and proactiveness and the association with other organizational variables (Hernández-Perlines et al., 2019; Basco et al., 2020). Innovativeness is a creative process potentially generating new ideas and innovations (Miller and Friesen, 1983; Lumpkin and Dess, 1996). Risk-taking involves the implementation of actions in search of potential profits, but with no probable expectation of success (Miller, 1983; Lumpkin and Dess, 1996). Proactiveness involved launching new products and services on the market before competing companies (Covin and Slevin, 1989; Rigtering et al., 2017).

Although both young and established firms can present different EO positions relative to performance (Messersmith and Wales, 2013; Palmer et al., 2019), the literature finds evidence that $\mathrm{EO}$ has a positive influence on firm performance (Shirokova et al., 2016; Basco et al., 2020; Galbreath et al., 2020). However, a gap exists in the literature on the importance of EO features in startups (Kee and Rahman, 2018) with evidence indicating that it can boost their performance in certain contexts (Lazzarotti et al., 2015; Migliori et al., 2019; Vaznyte and Andries, 2019). The literature suggests that several organizational attributes (e.g. strategy, resources and culture) and characteristics (e.g. environment and industry) that can shape the relationship of EO with performance (Lumpkin and Dess, 1996), which can differ for companies from different countries (Basco et al., 2020) and with different market orientations (Migliori et al., 2019). Thus, evidence for new contexts, such as startup firms, is needed to advance EO theory (Wales, 2016; Wales et al., 2019).

We know from the management accounting literature that several factors influence the adoption of MCS by startups (Davila and Foster, 2005; Davila et al., 2009). Based on organizational attributes (Covin and Wales, 2019), evidence suggests that EO can be important for the adoption of MCS elements (Daciê et al., 2017). This is because EO is associated with strategic formulation in organizations (Amit et al., 2000), as it can influence efficiency, growth, 
and innovation strategies (Callaway and Jagani, 2015). It thus has the potential to shape MCS. It has also been noted that companies with different EO levels apply different MCS to their innovation processes (Bisbe and Malagueño, 2015). Evidence also indicates that EO affects personnel control (Li et al., 2006). Since innovativeness, proactiveness, and risk-taking behavior (Miller, 1983; Covin and Slevin, 1989) are organizational attributes stemming from founders/managers' behavior, such an attitude could likely precede MCS adoption and help decision-making and allocation of resources and efforts (Davila et al., 2015). Therefore, an organization's EO stance could influence adoption of MCS elements to form different packages. We thus hypothesize that:

H2A: Entrepreneurial orientation in startup firms is positively associated with firm performance.

$\mathbf{H}_{2 \mathbf{B}}$ : Entrepreneurial orientation is associated with a package of MCS elements in startup firms.

\subsection{Mediating role of an MCS Package}

The relationship between EO and performance presents specific particularities for both young and mature companies (Messersmith and Wales, 2013; Palmer et al., 2019). It has been argued that several mechanisms may have an indirect effect on this relationship (Lumpkin and Dess, 1996; Hughes and Morgan, 2007). Research has also shown that the MCS package being used may be one of the mechanisms responsible for the mediation between EO and startup performance, as an MCS package can be shaped by EO (Li et al., 2006; Bisbe and Malagueño, 2015; Daciê et al., 2017), which can, simultaneously, boost performance (Davila and Foster, 2005; Cosenz and Noto, 2015; Bedford, 2015).

Al-Dhaafri and Al-Swidi (2014) show that enterprise resource planning systems can mediate EO and performance association. In addition, Daciê et al. (2017) found there were direct effects of EO on MCS use and firm performance as well as on performance through an MCS. Thus, there is reason to believe that the posture of startups, in relation to the EO dimensions of innovativeness, risk-taking, and proactiveness (Miller, 1983; Covin and Slevin, 1989), and their relationship with performance, is facilitated by an MCS package, which helps organizations to promote goal congruence to achieve the desired results (Malmi and Brown, 2008). Therefore, evidence suggests that EO indirectly influences performance, but can also be mediated by the MCS package. This leads us to the following hypothesis: 
H3: The elements included in a package of MCS mediates the relationship between entrepreneurial orientation and startup firm performance.

Based on the literature review and the hypotheses development, Figure 1 demonstrates the direct (solid arrows) and indirect (dashed arrow) relationships between the research constructs. Additionally, the model includes two control variables: firm age and sector.

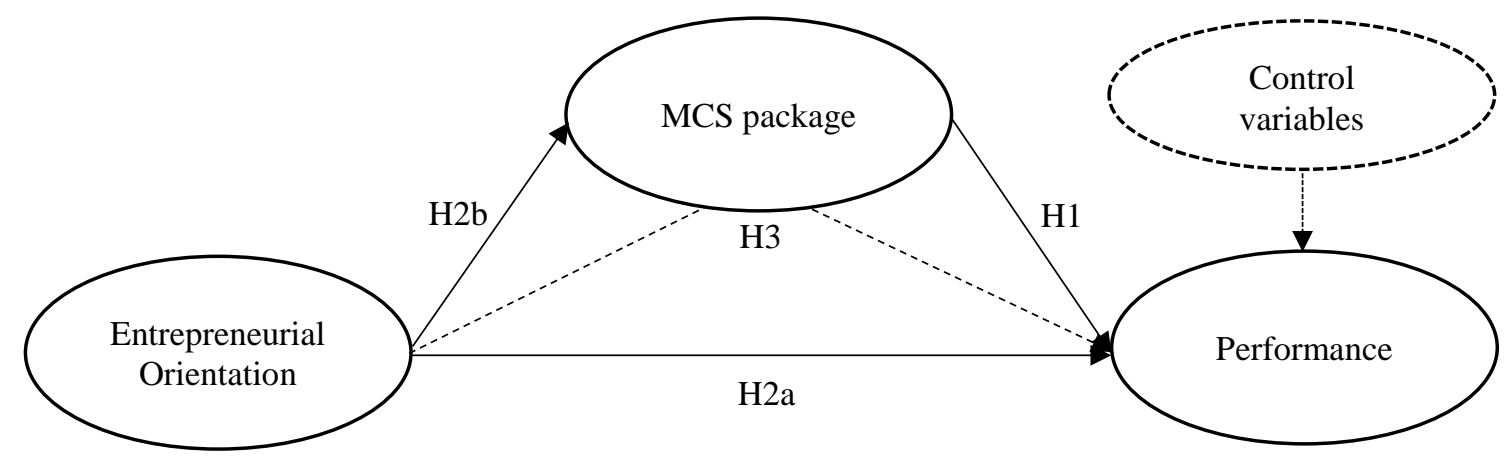

Figure 1. Conceptual model.

\section{Methodology}

\subsection{Data collection}

The study population comprises startups that exited 70 different Brazilian technologybased incubators or parks, which are important innovation ecosystems capable of assisting startup maturation (Latorre et al., 2017). The list of technology-based incubators or parks and respective startups was accessed through the National Association of Entities Promoting Innovative Enterprises (Anprotec), resulting in a population of 794 startups. Anprotec was created in 1987, and it has since been directly involved in the development of Brazilian technology-based incubators or parks (Anprotec, 2021). Incubators and parks in Brazil are relevant social and economic development drivers, similar to that in other countries (Plonski, 2016). Thus, startups acquire and exchange knowledge during the incubation period, which is crucial for their survival in the market after they exit (Phillips, 2002; Vick et al., 2013).

We followed the recommendations of Dillman et al. (2014) when conducting the survey questionnaire. For example, we included a cover letter and a personalized contact for each organization. In addition, we pretested the questionnaire with academics (two professors and three master's students in the area of management control) and managers (two startup managers and one manager from a large organization). The survey was sent to managers by e-mail and 
through social media (e.g. LinkedIn), from July to October 2019. In total, 100 startups completed the survey; no missing data or possible outliers were found through our exploratory analyses. The sample size $(\mathrm{n}=100)$ and response rate $(12.59 \%)$ are comparable with those of similar studies (Samagaio et al., 2018; Crespo et al., 2019). Of the sample, 59\% of the companies had exited an incubator or park within the last 5 years (2015-2019), while $68 \%$ of them were in the service sector, $2 \%$ in the commerce sector, and $30 \%$ of them from various industries, predominantly technology or engineering. At least $70 \%$ of respondents were company owners, $91 \%$ were senior executives, and $64 \%$ had at least one post-graduation degree.

\subsection{Measurements}

A 5-point Likert scale was used in our survey instrument, according to which EO was categorized as 1 = never; 5 = always, and MCS package and performance were categorized as $1=$ strongly disagree; 5 = strongly agree. EO was measured as a second-order construct, it had 9 items based on Miller (1983) and Lumpkin and Dess (1996) and validated in the Brazilian context by Lazzarotti et al. (2015). They encompassed innovativeness (three items), risk-taking (three items), and proactive (three items).

The MCS package is also a second-order construct based on 21 items developed and validated by Altoé et al. (2018), and it was based on Malmi and Brown (2008). It comprised cultural control (three items), planning (five items), cybernetic control (five items), rewards \& compensation (three items), and administrative control (five items). Performance was measured based on four items adopted from King et al. (2010) and Crespo et al. (2019). It consisted of a metric based on respondents' self-perception, which is compared to outcomes from the last 3 years. Such a method of quantifying performance has been widely accepted in the management literature (Lazzarotti et al., 2015; Crespo et al., 2019).

Two control variables were used in the study: firm age and sector. Firm age is its time in the market after its exit from the technology-based incubator or park. Firm age is a binary variable ( $\leq 5$ years and $>6$ years). Moreover, industry sector is a binary variable (commerce/services and industry). The management and accounting literatures highlight that a firm's age and the industry sector are important control variables (Bedford et al., 2019; Guenther and Heinicke, 2019; Kreilkamp et al., 2021; Scagnelli et al., 2019). 


\subsection{Analysis procedure}

Data were analyzed through structural equation modeling based on partial least squares (PLS-SEM) and fuzzy-set qualitative comparative analysis (fsQCA). Previous studies on MCS (Bedford et al., 2016; Samagaio et al., 2018; Crespo et al., 2019; Bedford, 2020; Frare and Beuren, 2021) and EO (Alonso-Dos-Santos and Llanos-Contreras, 2019; Kollmann et al., 2021) have demonstrated that the use of regression techniques in combination with fsQCA can provide complementary results based on the symmetric analytical properties of PLS-SEM and asymmetric analytical properties of fsQCA. Thus, the combined use of quantitative PLS-SEM and qualitative fsQCA techniques allows a broader view of the phenomenon (Venkatesh et al., 2013; Bedford, 2020) in addition to a complementary explanatory design (Johnson and Onwuegbuzie, 2004).

PLS-SEM was analyzed using SmartPLS software (3.0) (Ringle et al., 2015), which allows for the estimation of complex causal models with multiple dependent and independent, higher-order constructs, mediating variables, and control variables (Hair et al., 2017). PLSSEM is recommended for limited sample sizes, is robust for non-normal data, and it is widely used in management and business research (Hair et al., 2019). MCS research also commonly uses PLS-SEM (Rezania et al., 2016; Crespo et al., 2019; Kennedy and Widener, 2019).

FsQCA was performed in fsQCA 3.0 (Ragin, 2008), which assesses holistic interactions resulting in different configurations accounting for the success of the outcome (Fiss, 2007). FsQCA solutions promote equifinality by finding the causal conditions leading to the same result (Rihoux and Ragin, 2008). Previous studies have revealed the benefits of using fsQCA in MCS research (Bedford et al., 2016; Samagaio et al., 2018; Crespo et al., 2019; Frare and Beuren, 2021). Moreover, it has been argued that using fsQCA to explore MCS packages is necessary for understanding MCS combinations better (Bedford, 2020). Thus, fsQCA was used to identify the MCS package element combinations (first-order) and the EO dimensions (firstorder) accounting for startups' high performance.

Bedford (2020) has recently called for the examination of combinations of MCS elements using fsQCA in order to improve our knowledge of MCS packages. This is important as we need to better understand how different MCS combinations form packages of MCS which can lead to the same outcome (Bedford et al., 2016). Therefore, fsQCA allows us to analyze whether individual conditions are necessary and whether combinations of conditions are sufficient to achieve a given result (Bedford and Sandelin, 2015; Bedford et al., 2016). The combinations of conditions that appear in all solutions for the occurrence of a given result 
suggest complementarity, while the conditions that differ represent substitutability (Milgrom and Roberts, 1995; Bedford and Sandelin, 2015). Although the technique does not specify whether conditions are interdependent as described in the theory of Milgrom and Roberts (1995), they "indicate that certain attributes must combine to be sufficient for the outcome to occur; of additive (independent) or interactive (interdependent) associations" (Bedford and Sandelin, 2015, p. 22).

\subsection{Common-method bias and non-response bias}

Common-method bias (CMB) could be a potential problem as all variables are collected by the same survey-filled out by one respondent (Podsakoff et al., 2003). CMB was tested using 'Harman's single-factor test' (Harman, 1967) to assess the possible existence of this problem (Gomez-Conde et al., 2019; Matsuo et al., 2021). A single factor represented 28.03\% of the common variance. This value is below the $50 \%$ threshold required, this indicates that CMB is not a problem in our study (Podsakoff et al., 2003).

In contrast, as identifying the non-respondents' features was not possible, late respondents were assumed to be analogous to non-responders, and non-response bias was assessed by comparing the responses of early and late respondents (Abernethy et al., 2017; Gomez-Conde et al., 2019). Means of items of all constructs between the first and last ten respondents were compared (Mahama and Cheng, 2013); however, no significant differences were found between the groups ( $p>0.05$, two-tailed). Therefore, non-response bias was not an issue (de Harlez and Malagueño, 2016; Nuhu et al., 2019).

\section{Data analysis}

\subsection{PLS-SEM analysis}

\subsubsection{Measurement model}

Type I (reflective-reflective) higher-order constructs were measured through the repeated indicators' approach (Sarstedt et al., 2019). Previous studies measured EO (AlvarezTorres et al., 2019; Hernández-Perlines et al., 2020) and MCS packages (Rehman et al., 2020) as second-order Type I. Our second-order measurement model (Table I) evaluation was based on reflective indicator loadings, internal consistency reliability, and convergent and discriminant validity (Hair et al., 2019). The constructs and items (first-order) are shown in Appendix A. 
Table I

Measurement model

\begin{tabular}{lccccccccccc}
\hline Constructs & Mean & SD & $\boldsymbol{\alpha}$ & $\boldsymbol{\rho A}_{\mathbf{A}}$ & $\mathbf{C R}$ & $\mathbf{A V E}$ & $\mathbf{1}$ & $\mathbf{2}$ & $\mathbf{3}$ & $\mathbf{4}$ & $\mathbf{5}$ \\
\hline 1. EO & 3.65 & 0.88 & 0.795 & 0.806 & 0.821 & 0.607 & $\mathbf{0 . 7 7 9}$ & 0.397 & 0.645 & 0.145 & 0.215 \\
2. MCS package & 3.74 & 0.90 & 0.919 & 0.925 & 0.892 & 0.626 & 0.289 & $\mathbf{0 . 7 9 1}$ & 0.494 & 0.119 & 0.165 \\
3. Performance & 3.78 & 0.95 & 0.818 & 0.818 & 0.881 & 0.650 & 0.524 & 0.429 & $\mathbf{0 . 8 0 6}$ & 0.159 & 0.170 \\
4. Firm's age & - & - & - & - & - & - & -0.103 & 0.028 & -0.145 & - & 0.120 \\
5. Sector & - & - & - & - & - & - & 0.196 & 0.126 & 0.155 & 0.120 & - \\
\hline
\end{tabular}

Note 1: Fornell-Larcker criteria values are presented to the left/bottom diagonal, whereas heterotrait-monotrait ratio of correlations (HTMT) criteria values are shown on the right/top diagonal. Diagonal elements in bold are square roots of the average variance extracted (AVE).

Note 2: $\alpha=$ Cronbach's alpha, $\rho \mathrm{A}=$ Dijkstra-Henseler's rho, $\mathrm{CR}=$ composite reliability, AVE = average variance extracted.

For all items, the reflective indicator loadings were greater than 0.60 , which is said to meet adequacy requirements (Hair et al., 2017). Cronbach's alpha ( $\alpha$ ), Dijkstra-Henseler's rho $\left(\rho_{\mathrm{A}}\right)$, and composite reliability $(\mathrm{CR})$ ranged from 0.70 to 0.95 , which indicates internal consistency reliability (Hair et al., 2019). Convergent validity was shown by AVE, which was higher than 0.50 (Hair et al., 2019). Discriminant validity was attested using the heterotraitmonotrait ratio of correlations (HTMT) criterion, which recorded values lower than 0.85 (Hair et al., 2019) and by the Fornell-Larcker criterion, whose square root of AVE (diagonal values in bold) was higher than correlation between latent variables (Hair et al., 2017).

\subsubsection{Structural model}

The likelihood of multicollinearity in the structural model was evaluated based on the variance inflation factor (VIF), the model's predictive accuracy was calculated based on $\mathrm{R}^{2}$, and the model's predictive relevance was assessed based on Stone-Geisser $\left(\mathrm{Q}^{2}\right)$ (Hair et al., 2017). Table II presents the hypotheses, paths, beta coefficients $(\beta), t$-values, $p$-values, and confidence intervals (CIs).

Table II

Path analysis

\begin{tabular}{llllll}
\hline $\mathbf{H}$ & Paths & Beta $(\boldsymbol{\beta})$ & $\boldsymbol{t}$-value & $\boldsymbol{p}$-value & CI [5\%; 95\%]† \\
\hline $\mathrm{H}_{1}$ & MCS package $\rightarrow$ Performance & 0.307 & 3.410 & $0.001^{* * *}$ & {$[0.152 ; 0.448]$} \\
$\mathrm{H}_{2 \mathrm{~A}}$ & EO $\rightarrow$ Performance & 0.413 & 4.687 & $0.000 * * *$ & {$[0.248 ; 0.542]$} \\
$\mathrm{H}_{2 \mathrm{~B}}$ & EO $\rightarrow$ MCS package & 0.289 & 2.356 & $0.019 * *$ & {$[0.060 ; 0.470]$} \\
$\mathrm{H}_{3}$ & EO $\rightarrow$ MCS package $\rightarrow$ Performance & 0.089 & 1.667 & $0.095^{*}$ & {$[0.019 ; 0.195]$} \\
- & Firm's age & -0.117 & 1.354 & 0.176 & {$[-0.252 ; 0.031]$} \\
- & Sector & 0.050 & 0.547 & 0.584 & {$[-0.107 ; 0.192]$} \\
\hline
\end{tabular}

Note 1: $\dagger$ bias-corrected and accelerated (BCa) BCI; 5,000 subsamples; two-tailed test.

Note 2 : $* \mathrm{p}<0.10 ; * * \mathrm{p}<0.05 ; * * * \mathrm{p}<0.01$. 
Multicollinearity can likely occur between latent variables when VIF is higher than 3.00 (Hair et al., 2019). The recorded VIFs ranged from 1.000 to 1.145 , which implies an absence of multicollinearity. The explained variance of the endogenous variables $\left(\mathrm{R}^{2}\right)$ could have been small $(2 \%)$, medium (13\%), or large (26\%) (Cohen, 1988). Thus, the MCS $\mathrm{R}^{2}$ was low to medium $(7.4 \%)$ and high for performance $(34.6 \%) . \mathrm{Q}^{2}$ values higher than 0 were acceptable (Hair et al., 2019). Thus, MCS (2.9\%) and performance (22.7\%) values highlighted the model's predictive relevance.

\subsection{FsQCA analysis}

FsQCA analysis was used in addition to PLS-SEM. It was mainly adopted for exploring the combinations of MCS in different packages and EO dimensions, leading to high startup performance. Three steps were followed to do this, the first stage consisted of calibrating the mean of the constructs between values 0 and 1, the second stage consisted of analyzing the causal conditions necessary to arrive at a certain outcome, while the third stage consisted of analyzing conditions sufficient to promote dependent variable success (Ragin, 2008). Despite all the research on the symmetrical relationship between MCS and other variables, few studies have explored how combinations of MCS elements in a package are used by companies (Bedford and Malmi, 2015; Bedford, 2020). Different combinations can occur in different firm types, due to the dimensions of EO (Covin and Wales, 2019). Therefore, fsQCA can be used to explore EO dimension combinations and MCS package elements to understand what leads to high startup performance.

\subsubsection{Calibration}

Calibration is the first step in an fsQCA analysis. The mean of the constructs (5-point Likert scale) must be calibrated to values between 0 and 1 (Ragin, 2008). According to theoretical knowledge of research constructs (Ragin, 2008) and previous studies (Palmer et al., 2019; Hock-Doepgen et al., 2020), calibration consists of turning original points 5, 3, and 1 into full membership (95\%), cross-over (50\%), and full non-membership (5\%).

\subsubsection{Necessary conditions}

The second stage consists of analyzing the causal conditions necessary for obtaining a certain outcome (Ragin, 2008). Conditions based on consistency higher than 0.90 are necessary, and those between 0.80 and 0.90 are almost always necessary (Ragin, 2000). Based on Table 
III, innovativeness is a necessary condition, with proactiveness almost always necessary, while the MCS elements of cultural control, planning control, and reward \& compensation are almost always necessary for high startups performance. However, although a condition is always or almost always necessary, it may not be sufficient, depending on combinations with other conditions (Ragin, 2008).

\section{Table III}

Necessary conditions

\begin{tabular}{llcc}
\hline Second-order & First-order conditions & Consistency & Coverage \\
\hline EO & Innovativeness & $\mathbf{0 . 9 1 2}$ & 0.875 \\
& $\sim$ Innovativeness & 0.293 & 0.907 \\
& Risk-taking & 0.700 & 0.912 \\
& $\sim$ Risk-taking & 0.513 & 0.857 \\
& Proactiveness & $\mathbf{0 . 8 8 9}$ & 0.900 \\
& $\sim$ Proactiveness & 0.330 & 0.875 \\
MCS package & Cultural control & $\mathbf{0 . 8 6 4}$ & 0.872 \\
& $\sim$ Cultural control & 0.328 & 0.875 \\
& Planning & $\mathbf{0 . 8 9 1}$ & 0.883 \\
& $\sim$ Planning & 0.325 & 0.911 \\
& Cybernetic control & 0.795 & 0.921 \\
& $\sim$ Cybernetic control & 0.420 & 0.835 \\
& Reward and compensation & $\mathbf{0 . 8 0 7}$ & 0.871 \\
& $\sim$ Reward and compensation & 0.384 & 0.874 \\
& Administrative control & 0.777 & 0.902 \\
& $\sim$ Administrative control & 0.457 & 0.908 \\
\hline
\end{tabular}

Note: The tilde ( ) before the causal condition represents the condition's absence.

\subsubsection{Sufficient conditions}

The third stage consists of analyzing the conditions sufficient to promote dependent variable success (Ragin, 2008). Therefore, a truth table with $2^{\mathrm{k}}$ rows was created, where $k$ is the number of causal conditions, that is, $2^{8}$ rows (Ragin, 2008). The results were analyzed based on the intermediate solution (Table IV), as suggested in the literature (Alonso-Dos-Santos and Llanos-Contreras, 2019; Covin et al., 2020). A consistency threshold above 0.80 (0.944) resulted in four causal combinations (solutions) (Ragin, 2008).

Raw coverage $(0.274-0.627)$ represents the ratio of membership in the outcome, explained by each solution. Unique coverage $(0.012-0.020)$ explains the ratio of cases covered only by the solution. Solution coverage is the ratio of cases explained by the combination of all solutions, that is, $74.7 \%$ of cases were explained by the four solutions. All consistencies $(0.959$ $0.999)$ were higher than the threshold (0.80) and solution consistency was also higher than 0.80 
(0.922), this finding demonstrates the adequacy of solutions found through fsQCA (Ragin, 2008).

\section{Table IV}

Sufficient conditions for high performance

\begin{tabular}{|c|c|c|c|c|}
\hline \multirow[t]{2}{*}{ Conditions } & \multicolumn{4}{|c|}{ High performance } \\
\hline & $\mathrm{S} 1$ & $\mathrm{~S} 2$ & S3 & $\mathrm{S} 4$ \\
\hline Innovativeness & $\bullet$ & $\bullet$ & $\bullet$ & \\
\hline Risk-taking & & & $\bullet$ & $\otimes$ \\
\hline Proactiveness & $\bullet$ & & $\bullet$ & $\bullet$ \\
\hline Cultural control & $\bullet$ & $\bullet$ & $\bullet$ & $\bullet$ \\
\hline Planning & $\bullet$ & $\bullet$ & $\bullet$ & $\bullet$ \\
\hline Cybernetic control & $\bullet$ & $\bullet$ & & $\bullet$ \\
\hline Reward and compensation & • & • & $\otimes$ & $\bullet$ \\
\hline Administrative control & & $\bullet$ & $\bullet$ & $\bullet$ \\
\hline Raw coverage & 0.627 & 0.601 & 0.274 & 0.405 \\
\hline Unique coverage & 0.020 & 0.017 & 0.012 & 0.012 \\
\hline Consistency & 0.964 & 0.959 & 0.999 & 0.985 \\
\hline Overall solution coverage & \multicolumn{4}{|c|}{0.747} \\
\hline Overall solution consistency & \multicolumn{4}{|c|}{0.922} \\
\hline
\end{tabular}

Note 1: Full black circles $(\bullet)$ indicate causal condition, and white circles with " $\mathrm{x}$ " in the center $(\otimes)$ indicate causal condition absence. Blank cells represent "do not care".

Note 2: This table excludes solutions with a unique coverage less than 0.00 .

\section{Discussion and conclusions}

\subsection{Discussion of results}

The first hypothesis $\left(\mathrm{H}_{1}\right)$ suggests that the adoption of an MCS package is positively associated with firm performance. $\mathrm{H}_{1}$ was confirmed $(\beta=0.307 ; \mathrm{p}<0.01)$, and it corroborated the findings of previous studies (Davila and Foster, 2005; Cosenz and Noto, 2015; Bedford, 2015). This finding highlights the need for entrepreneurial companies to adopt an MCS package (Akroyd et al., 2019) and shows that technology-based parks and incubator environments may have helped the management control adoption process (Davila, 2019). It also suggests that MCS packages may represent a way for startups to face early-stage impairments and survive in the market (Davila et al., 2015; Cantamessa et al., 2018).

The fsQCA analysis showed that cultural control, planning control, and reward \& compensation are almost always necessary; however, they are not sufficient by themselves. Therefore, two (S2 and S4) of the four high-performance combinations contained all the MCS package elements. All elements, except administrative control, which is indifferent, was observed in S1, while there was an indifference of cybernetic controls and an absence of rewards \& compensation in S3. Cultural control and planning control were the only MCS 
elements observed in all solutions, suggesting complementarity (Milgrom and Roberts, 1995; Bedford and Sandelin, 2015) and their importance for startup firm performance.

The presence of cultural control can be understood in relation to the dynamics of new ventures, which cannot easily adopt other MCS if cultural control is not yet embodied by employees (Akroyd et al., 2019). Cultural control is the means of communicating a startups' fundamental values (Malmi and Brown, 2008). It influences employees' motivation and behavior (Heinicke et al., 2016) and is a driver for other organizational changes (Marginson, 2009). Thus, cultural control is an important socialization mechanism for achieving goal congruence (Akroyd and Maguire, 2011; Kennedy and Widener, 2019). The presence of planning controls in all MCS packages allows us to infer that they operate in a complementary way as startups aim to guide employees' behavior to achieve previously established goals (Malmi and Brown, 2008) in order to promote high performance.

The other MCS elements were found in at least three of the four solutions. Cybernetic control and administrative control are present in 3 solutions and indifferent in one. Rewards \& compensation are present in 3 solutions and absent in one. This suggests possible substitutability between these elements, depending on combinations with other elements (Milgrom and Roberts, 1995; Bedford and Sandelin, 2015). Bedford et al. (2016) reveal that the substitutability of MCS elements differs by strategic context (defenders $v s$. prospectors), and our findings suggest that this substitutability is shaped according to the firm's EO profile. For example, S3 is the only solution that has the presence of risk-taking. In addition to the complementarity of cultural control and planning, only administrative controls are present. This reinforces that the presence of governance and organizational structures, and formalization of policies and procedures (administrative control) is crucial to deal with risk-taking (Rikhardsson et al., 2021), which seems sufficient and does not require the adoption of other MCS elements.

In fact, what we can see is that startups start to adopt these MCS elements according to the perceived need in their birth and growth stages, and these elements start to act in combination with the other elements forming a package of MCS (Akroyd et al., 2019). This is consistent with the idea that cultural controls guide and are supported by the adoption of other controls (Akroyd and Kober, 2020). Overall, our findings have demonstrated that employing elements of the MCS package which then act in combination which each other are effective. We also highlight the existence of more than one combination of MCS elements which are capable of promoting equifinality in relation to organizations' objectives. 
The $\mathrm{H}_{2 \mathrm{~A}}$ hypothesis proposed that EO is positively associated with firm performance, which was statistically supported $(\beta=0.413 ; \mathrm{p}<0.01)$. This finding corroborated the findings of previous studies (Migliori et al., 2019; Vaznyte and Andries, 2019; Basco et al., 2020; Galbreath et al., 2020). Similar to the results of the fsQCA analysis, innovativeness and proactiveness were always and almost always necessary, respectively. However, none of these conditions was self-sufficient in a singular way. Innovativeness (S1, S2, and S3) and proactiveness (S1, S3, and S4) are present in three of the four solutions; however, innovativeness is indifferent in S4 and proactiveness in S2. Risk-taking, in turn, was observed in S3, absent in S4, and indifferent in S1 and S2. There was at least one EO dimension in all solutions, and only S3 contained all three dimensions. Innovativeness and proactiveness tend to have a stronger impact on performance in small-and medium-sized companies than risktaking. Thus, different EO combinations can result in high-performance startups, mainly because of innovativeness and/or proactiveness.

The fsQCA analysis highlighted the interface (combinations) between EO dimensions and MCS package elements sufficient to promote high organizational performance. EO dimensions were observed in all four solutions with MCS package elements, and this outcome reinforced the perspective on the importance of the interface between EO and MCS packages (Li et al., 2006; Bisbe and Malagueño, 2015; Daciê et al., 2017). These findings show that different combinations of EO dimensions and different MCS packages can create equifinality and thus enable high performance in startup firms.

$\mathrm{H}_{2 \mathrm{~B}}$ argues that EO is positively associated with a package of MCS elements, supporting this hypothesis $(\beta=0.289 ; \mathrm{p}<0.05)$, which is in line with evidence in the literature (Li et al., 2006; Daciê et al., 2017). Thus, the dimensions of EO (innovativeness, proactiveness, and risktaking) are antecedent to MCS package adoption in startups. Besides EOs associated with an organizations' strategic position (Amit et al., 2000), it also boosts efficiency, growth, and innovation (Callaway and Jagani, 2015), and influences the adoption of management mechanisms essential for market development (Davila et al., 2015). $\mathrm{H}_{2 \mathrm{~B}}$ 's confirmation reinforced the idea that behavioral elements play a relevant role in defining MCS packages.

$\mathrm{H}_{3}$ proposes that the MCS package mediates the relationship between EO and firm performance which was not rejected $(\beta=0.089 ; \mathrm{p}<0.10)$. Thus, in addition to the direct impact of EO on the MCS package, and of such a package on performance, we can infer that EO also has an indirect effect on performance due to the MCS package's mediation. We found a 
complementary mediation (partial mediation), given the positive and significant direct and indirect (mediated by the MCS package) effect of EO on performance (Hair et al., 2017).

This finding is corroborated by Daciê et al. (2017), who found direct and indirect EO effects on performance based on management mechanisms. Furthermore, this finding supports the expectations of Lumpkin and Dess (1996) as it shows a mediating effect on the relationship between EO and performance. Therefore, the MCS package plays an important role in helping match EO and performance in the startup firm context. This implies that EO, with the existence of certain levels of innovativeness, risk-taking and proactiveness (Miller, 1983), is a critical factor for the adoption of an MCS package in startups, and that this package translates business posture into firm performance. In addition to the overall posture of EO affecting the adoption of the MCS package, the specific combination of its EO dimensions (innovativeness, risktaking and proactiveness) with certain MCS elements, enables high performance. These different configurations vary according to the context and the profile of a startup, and show us the different paths these firms take to achieve high performance (Fiss, 2007).

\subsection{Conclusions}

In conclusion we found that the relationship between EO and an MCS package influences startup performance. As EO influenced MCS package adoption it thus plays an important role in the management of startup firms. We also found that the MCS package mediates the relationship between EO and performance. Therefore, the MCS package was able to translate startups' EO into performance, i.e., it facilitates innovativeness, risk-taking and proactiveness to achieve better performance. Our fsQCA results showed that there was a necessary condition (innovativeness) and almost always necessary condition (proactiveness, cultural control, planning control and reward \& compensation) to promote high performance in startups, but that they are not sufficient by themselves, just only when combined. Thus, fsQCA showed four solutions capable of promoting equifinality to help achieve high performance. In all solutions, cultural controls and planning were complementary and were always present, which reinforces the importance of these two elements of an MCS package for the success of startup firms. These solutions encompassed the interface between EO dimensions and MCS package elements, highlighting which configurations lead to high startup firm performance. 


\subsection{Theoretical implications}

This study contributes to the literature on MCS adoption by startups (Davila and Foster, 2005, 2007; Davila et al., 2009; Davila et al., 2015; Samagaio et al., 2018; Crespo et al., 2019; Pavlatos, 2021), and provides new evidence regarding the importance of the interface between EO dimensions and MCS elements (Li et al., 2006; Bisbe and Malagueño, 2015; Daciê et al., 2017). It also contributes by reinforcing the importance of having the MCS package acting in balance with "controls working together, interdependently, in a complementary fashion" (Akroyd et al., 2019, p. 1805) and extends this research by showing the different MCS packages that can enable high performance in startup firms. Furthermore, we contribute to the literature on EO and performance (Lumpkin and Dess, 1996) by highlighting how an MCS package acts as a mediating variable necessary to achieve high performance in startup firms. Our fsQCA results corroborated our understanding of equifinality in MCS combinations (Bedford et al., 2016; Bedford, 2020) as it demonstrated the complementarity/substitutability between MCS package elements (Malmi and Brown, 2008). Overall, this study has contributed to explaining the importance of startups adopting an MCS package, by showing how the symmetric (PLSSEM) and asymmetric (fsQCA) relationships help these entrepreneurial companies to achieve high performance rates.

\subsection{Managerial implications}

This investigation has managerial implications for entrepreneurial ecosystem actors. First, for entrepreneurs, managers, and startup founders, the results highlight the relevance of having these firms adopt an MCS package which has cultural and planning controls and being concerned with their EO attitudes. Depending on the interface between the dimensions of EO and the elements of the MCS package, different combinations can help startups achieve a high level of performance. Thus, a startups' management needs to be reflexive of these solutions as they promote equifinality which enables high performance. Finally, technology park/incubator managers should consider managerial knowledge transfer, emphasizing the relevance of cultural and planning controls (observed in all high-performance solutions) and adopt structured policies to make sure that startup firms have these in place before they exit.

\subsection{Policy-making implications}

Startups can potentially shape our economic future (Walsh and Cunningham, 2016); however, many of them fail to do so and face bankruptcy in their early stages (Cantamessa et 
$a l ., 2018)$. Therefore, understanding the dimensions of EO and MCS package elements is useful for policymakers so as to help startup firms manage the context they face, promote better performance, and consequently, achieve successful outcomes. Furthermore, there are many policies that are necessary to support startups, such as the use of managerial and financial information to evaluate companies and distribute funding. There is evidence that external financiers attach considerable importance to startups' financial MCS elements when deciding whether or not to fund those (Schachel et al., 2021). Thus, information about the combinations of MCS packages that are adopted and lead to startups' success is relevant for these decision makers.

\subsection{Limitations and future research}

This study has some limitations that could be addressed in future research. Being careful in generalizing data is essential, since the sample only included Brazilian startups that have exited from technology-based parks and incubators. Our study does not consider startups that exited from business accelerators, which are a recent ecosystem for supporting new businesses (Del Sarto et al., 2020). More research analyzing the MCS adoption of startups for each entrepreneurial ecosystem (incubator, park, accelerators, etc.) would help us to understand the role of each ecosystem in supporting the formation of a startup's MCS package.

Our study analyzes the elements of the MCS package in startups; however, the data are transversal and do not allow for analysis of causality and temporal evolution. Therefore, a suggestion for further research is to use longitudinal and/or qualitative approaches to improve our understanding of how the MCS package design and implementation process could best support the growth and performance of startups. This would help us to better understand the theory of how different startups adopt and use an MCS package over time (Berg and Madsen, 2020). Furthermore, it would be interesting to examine the evolution of the MCS package elements over time using fsQCA, adding specific proxies to capture temporality (Bedford, 2020).

We measure EO based on three dimensions: innovativeness, proactiveness, and risktaking. Although these three dimensions form the traditional and predominant approach (Wales et al., 2019), some authors, such as Lumpkin and Dess (1996), have recommend using the two other dimensions - autonomy and competitive aggressiveness, which could be included in future research. Finally, our measure of performance in this study consisted of a self-reported measure 
by the respondents. Therefore, future research could include other measures of performance, such as market share or financial measures.

\section{References}

Abernethy, M.A., Bouwens, J. and Kroos, P. (2017), "Organization identity and earnings manipulation”, Accounting, Organizations and Society, Vol. 58, pp. 1-14. http://doi.org/10.1016/j.aos.2017.04.002

Akroyd, C. and Kober, R. (2020), "Imprinting founders' blueprints on management control systems", Management Accounting Research, Vol. 46, pp. 1-18, 100645. http://doi.org/10.1016/j.mar.2019.07.002

Akroyd, C., Kober, R. and Li, D. (2019), "The emergence of management controls in an entrepreneurial company", Accounting \& Finance, Vol. 59 No. 3, pp. 1805-1833. http://doi.org/10.1111/acfi.12477

Akroyd, C. and Maguire, W. (2011), "The roles of management control in a product development setting", Qualitative Research in Accounting \& Management, Vol. 8 No. 3, pp. 212-237. https://doi.org/10.1108/11766091111162061

Al-Dhaafri, H.S. and Al-Swidi, A.K. (2014), "The entrepreneurial orientation and the organizational performance: do enterprise resource planning systems have a mediating role? A study on Dubai police”, Asian Social Science, Vol. 10 No. 2, pp. 257-272. http://doi.org/10.5539/ass.v10n2p257

Alonso-Dos-Santos, M. and Llanos-Contreras, O. (2019), "Family business performance in a post-disaster scenario: the influence of socioemotional wealth importance and entrepreneurial orientation", Journal of Business Research, Vol. 101, pp. 492-498. http://doi.org/10.1016/j.jbusres.2018.12.057

Altoé, S.M.L., Pacheco, V. and Espejo, M.M.S.B. (2018), "Leadership styles and the use of the management control system: evidences of top managers training level", Advances in Scientific and Applied Accounting, Vol. 11 No. 2, pp. 224-245. http://doi.org/10.14392/ASAA.2018110203

Alvarez-Torres, F.J., Lopez-Torres, G.C. and Schiuma, G. (2019), "Linking entrepreneurial orientation to SMEs' performance”, Management Decision, Vol. 57 No. 12, pp. 3364-3386. http://doi.org/10.1108/MD-11-2018-1234

Amit, R., Brigham, K. and Markman, G. (2000), "Entrepreneurial management as strategy", Meyer G.D. and Heppard K. (Eds.), Entrepreneurship as Strategy: Competing on the Entrepreneurial Edge, Sage Publications, Newbury Park, CA, pp. 83-100.

Anprotec. (2021), About the National Association of Entities Promoting Innovative Enterprises. Retrieved from: https://anprotec.org.br/site/sobre/

Basco, R., Hernández-Perlines, F. and Rodríguez-García, M. (2020), "The effect of entrepreneurial orientation on firm performance: a multigroup analysis comparing China, Mexico, and Spain", Journal of Business Research, Vol. 113, pp. 409-421. http://doi.org/10.1016/j.jbusres.2019.09.020

Bedford, D.S. (2015), "Management control systems across different modes of innovation: implications for firm performance", Management Accounting Research, Vol. 28, pp. 12-30. http://doi.org/10.1016/j.mar.2015.04.003

Bedford, D.S. (2020), "Conceptual and empirical issues in understanding management control combinations", Accounting, Organizations and Society, Vol. 86, pp. 1-8, 101187. http://doi.org/10.1016/j.aos.2020.101187 
Bedford, D.S., Bisbe, J. and Sweeney, B. (2019), "Performance measurement systems as generators of cognitive conflict in ambidextrous firms", Accounting, Organizations and Society, Vol. 72, pp. 21-37. http://doi.org/10.1016/j.aos.2018.05.010

Bedford, D.S. and Malmi, T. (2015), "Configurations of control: an exploratory analysis", Management Accounting Research, Vol. 27, pp. 2-26.

http://doi.org/10.1016/j.mar.2015.04.002

Bedford, D.S., Malmi, T. and Sandelin, M. (2016), "Management control effectiveness and strategy: an empirical analysis of packages and systems", Accounting, Organizations and Society, Vol. 51, pp. 12-28. http://doi.org/10.1016/j.aos.2016.04.002

Bedford, D.S. and Sandelin, M. (2015), "Investigating management control configurations using qualitative comparative analysis: an overview and guidelines for application", Journal of Management Control, Vol. 26 No. 1, pp. 5-26. http://doi.org/10.1007/s00187-015-02043

Berg, T. and Madsen, D.Ø. (2020), "The evolution of a management control package: a retrospective case study", Journal of Applied Accounting Research, Vol. 21 No. 4, pp. 763 781. https://doi.org/10.1108/JAAR-10-2019-0148

Bikse, V., Lusena-Ezera, I. and Rivza, B. (2018), "Innovative start-ups: challenges and development opportunities in Latvia", International Journal of Innovation Science, Vol. 10 No. 2, pp. 261-273. http://doi.org/10.1108/IJIS-05-2017-0044

Bisbe, J. and Malagueño, R. (2015), "How control systems influence product innovation processes: examining the role of entrepreneurial orientation", Accounting and Business Research, Vol. 45 No. 3, pp. 356-386. http://doi.org/10.1080/00014788.2015.1009870

Callaway, S.K. and Jagani, S.B. (2015), "The impact of banks' entrepreneurial orientation on strategic control systems", American Journal of Business, Vol. 30 No. 1, pp. 49-71. http://doi.org/10.1108/AJB-10-2013-0067

Cantamessa, M., Gatteschi, V., Perboli, G. and Rosano, M. (2018), "Startups' roads to failure", Sustainability, Vol. 10 No. 7, pp. 2346. http://doi.org/10.3390/su10072346

Cohen, J. (1988), Statistical Power Analysis for the Behavioral Sciences, Lawrence Erlbaum Associates, Mahwah.

Cosenz, F. and Noto, L. (2015), "Combining system dynamics modelling and management control systems to support strategic learning processes in SMEs: a dynamic performance management approach”, Journal of Management Control, Vol. 26 No. 2-3, pp. 225-248. http://doi.org/10.1007/s00187-015-0208-z

Covin, J.G., Rigtering, J.C., Hughes, M., Kraus, S., Cheng, C.F. and Bouncken, R.B. (2020), "Individual and team entrepreneurial orientation: scale development and configurations for success", Journal of Business Research, Vol. 112, pp. 1-12. http://doi.org/10.1016/j.jbusres.2020.02.023

Covin, J.G., Slevin, D.P. (1989), "Strategic management of small firms in hostile and benign environments", Strategic Management Journal, Vol. 10 No. 1, pp. 75-87. http://doi.org/10.1002/smj.4250100107

Covin, J.G. and Wales, W.J. (2019), "Crafting high-impact entrepreneurial orientation research: Some suggested guidelines”, Entrepreneurship Theory and Practice, Vol. 43 No. 1, pp. $3-$ 18. http://doi.org/10.1177/1042258718773181

Crespo, N.F., Rodrigues, R., Samagaio, A. and Silva, G.R. (2019), "The adoption of management control systems by start-ups: internal factors and context as determinants", Journal of Business Research, Vol. 101, pp. 875-884.

http://doi.org/10.1016/j.jbusres.2018.11.020 
Daciê, F.D.P., Espejo, M.M.D.S.B., Gimenez, F.A.P. and Camacho, R.R. (2017), “Are similar ones different? Determinant characteristics of management tool usage within companies sharing the same institutional environment", RAUSP Management Journal, Vol. 52 No. 3, pp. 341-352. http://doi.org/10.1016/j.rausp.2017.05.006

Davila, A. (2019), "Emerging themes in management accounting and control research", Spanish Accounting Review, Vol. 22 No. 1, pp. 1-5. http://doi.org/10.6018/rcsar.22.1.354371

Davila, A. and Foster, G. (2005), "Management accounting systems adoption decisions: evidence and performance implications from early-stage/startup companies", The Accounting Review, Vol. 80 No. 4, pp. 1039-1068.

http://doi.org/10.2308/accr.2005.80.4.1039

Davila, A. and Foster, G. (2007), "Management control systems in early-stage startup companies", The Accounting Review, Vol. 82 No. 4, pp. 907-937. http://doi.org/10.2308/accr.2007.82.4.907

Davila, A., Foster, G. and Jia, N. (2015), "The valuation of management control systems in start-up companies: international field-based evidence", European Accounting Review, Vol. 24 No. 2, pp. 207-239. http://doi.org/10.1080/09638180.2014.965720

Davila, A., Foster, G. and Li, M. (2009), "Reasons for management control systems adoption: insights from product development systems choice by early-stage entrepreneurial companies", Accounting, Organizations and Society, Vol. 34 No. 3-4, pp. 322-347. http://doi.org/10.1016/j.aos.2008.08.002

de Harlez, Y. and Malagueño, R. (2016), "Examining the joint effects of strategic priorities, use of management control systems, and personal background on hospital performance", Management Accounting Research, Vol. 30, pp. 2-17. http://doi.org/10.1016/j.mar.2015.07.001

Del Sarto, N., Isabelle, D.A. and Di Minin, A. (2020), "The role of accelerators in firm survival: An fsQCA analysis of Italian startups", Technovation, Vol. 90-91, pp. 1-13, 102102. http://doi.org/10.1016/j.technovation.2019.102102

Dillman, D.A., Smyth, J.D. and Christian, L.M. (2014), Internet, Phone, Mail, and Mixed-Mode Surveys: The Tailored Design Method. John Wiley and Sons, Hoboken, New Jersey.

Fiss, P.C. (2007), "A set-theoretic approach to organizational configurations", Academy of Management Review, Vol. 32 No. 4, pp. 1180-1198. http://doi.org/10.5465/amr.2007.26586092

Frare, A.B. and Beuren, I.M. (2021), "Fostering individual creativity in startups: comprehensive performance measurement systems, role clarity and strategic flexibility", European Business Review, Ahead-of-print. http://doi.org/10.1108/EBR-11-2020-0262

Galbreath, J., Lucianetti, L., Thomas, B. and Tisch, D. (2020), "Entrepreneurial orientation and firm performance in Italian firms", International Journal of Entrepreneurial Behavior and Research, Vol. 26 No. 4, pp. 629-646. http://doi.org/10.1108/IJEBR-07-2019-0457

Gomez-Conde, J., Lunkes, R.J. and Rosa, F.S. (2019), "Environmental innovation practices and operational performance", Accounting, Auditing \& Accountability Journal, Vol. 32 No. 5, pp. 1325-1357. http://doi.org/10.1108/AAAJ-01-2018-3327

Grabner, I. and Moers, F. (2013), "Management control as a system or a package? Conceptual and empirical issues", Accounting, Organizations and Society, Vol. 38 No. 6-7, pp. 407-419. https://doi.org/10.1016/j.aos.2013.09.002

Guenther, T.W. and Heinicke, A. (2019), "Relationships among types of use, levels of sophistication, and organizational outcomes of performance measurement systems: the crucial role of design choices", Management Accounting Research, Vol. 42, 1-25. http://doi.org/10.1016/j.mar.2018.07.002 
Hair, J.F., Risher, J.J., Sarstedt, M. and Ringle, C.M. (2019), "When to use and how to report the results of PLS-SEM", European Business Review, Vol. 31 No. 1, pp. 2-24. http://doi.org/10.1108/EBR-11-2018-0203

Hair, J.F., Hult, G.T.M., Ringle, C. and Sarstedt, M. (2017), A Primer on Partial Least Squares Structural Equation Modeling (PLS-SEM): Second edition. Sage, Los Angeles.

Harman, H.H. (1967), Modern Factor Analysis. The University of Chicago Press, Chicago.

Heinicke, A., Guenther, T.W. and Widener, S.K. (2016), "An examination of the relationship between the extent of a flexible culture and the levers of control system: the key role of beliefs control", Management Accounting Research, Vol. 33, pp. 25-41.

http://doi.org/10.1016/j.mar.2016.03.005

Hernández-Perlines, F., Ariza-Montes, A. and Araya-Castillo, L. (2020), "Socioemotional wealth, entrepreneurial orientation and international performance of family firms", Economic Research-Ekonomska Istraživanja, Vol. 33 No. 1, pp. 3125-3145. http://doi.org/10.1080/1331677X.2019.1685398

Hernández-Perlines, F., Moreno-García, J. and Yáñez-Araque, B. (2019), “The influence of socioemotional wealth in the entrepreneurial orientation of family businesses", International Entrepreneurship and Management Journal, Vol. 15 No. 2, pp. 523-544. http://doi.org/10.1007/s11365-019-00561-0

Hock-Doepgen, M., Clauss, T., Kraus, S. and Cheng, C.F. (2020), "Knowledge management capabilities and organizational risk-taking for business model innovation in SMEs", Journal of Business Research, Vol. 130, pp. 683-697. http://doi.org/10.1016/j.jbusres.2019.12.001

Hughes, M. and Morgan, R.E. (2007), "Deconstructing the relationship between entrepreneurial orientation and business performance at the embryonic stage of firm growth", Industrial Marketing Management, Vol. 36 No. 5, pp. 651-661. http://doi.org/10.1016/j.indmarman.2006.04.003

Janka, M. (2021), "Enabling formal MCS design and use: a meta-synthesis of qualitative research", Journal of Accounting \& Organizational Change, Vol. 17 No. 2, pp. 133-163. https://doi.org/10.1108/JAOC-01-2019-0002

Johnson, R.B. and Onwuegbuzie, A.J. (2004), "Mixed methods research: a research paradigm whose time has come", Educational Researcher, Vol. 33 No. 7, pp. 14-26. http://doi.org/10.3102/0013189X033007014

Jukka, T. and Pellinen, J. (2020), "Exploring management control system typologies: an organisation-level view", Journal of Accounting \& Organizational Change, Vol. 16 No. 3, pp. 427-445. http://doi.org/10.1108/jaoc-11-2019-0116

Kee, D.M.H. and Rahman, N.A. (2018), "Effects of entrepreneurial orientation on start-up success: a gender perspective", Management Science Letters, Vol. 8 No. 6, pp. 699-706. http://doi.org/10.5267/j.msl.2018.4.012

Kennedy, F.A. and Widener, S.K. (2019), "Socialization mechanisms and goal congruence", Accounting, Organizations and Society, Vol. 76, pp. 32-49.

http://doi.org/10.1016/j.aos.2019.01.004

King, R., Clarkson, P.M., and Wallace, S. (2010), "Budgeting practices and performance in small healthcare businesses", Management Accounting Research, Vol. 21 No. 1, pp. 40-55. http://doi.org/10.1016/j.mar.2009.11.002

Kollmann, T., Stöckmann, C., Niemand, T., Hensellek, S. and de Cruppe, K. (2021), “A configurational approach to entrepreneurial orientation and cooperation explaining product/service innovation in digital vs. non-digital startups", Journal of Business Research, Vol. 125, pp. 508-519. http://doi.org/10.1016/j.jbusres.2019.09.041

Kreilkamp, N., Schmidt, M. and Wöhrmann, A. (2021), "Debiasing as a powerful management accounting tool? Evidence from German firms", Journal of Accounting \& Organizational Change, Vol. 17 No. 4, pp. 555-582. http://doi.org/10.1108/JAOC-12-2019-0122 
Latorre, M.P., Hermoso, R. and Rubio, M.A. (2017), "A novel network-based analysis to measure efficiency in science and technology parks: the ISA framework approach", The Journal of Technology Transfer, Vol. 42 No. 6, pp. 1255-1275. http://doi.org/10.1007/s10961-017-9585-9

Lazzarotti, F., Silveira, A.L.T., Carvalho, C.E., Rossetto, C.R. and Sychoski, J.C. (2015), "Entrepreneurial orientation: a study of dimensions and its relationship with performance at firms graduating from incubators", Revista de Administração Contemporânea, Vol. 19 No. 6, pp. 673-695. http://doi.org/10.1590/1982-7849rac20151829.

Lin, Y.H., Chen, C.J. and Lin, B.W. (2017), "The influence of strategic control and operational control on new venture performance", Management Decision, Vol. 55 No. 5, pp. 1042-1064. http://doi.org/10.1108/MD-07-2015-0324

Lumpkin, G.T. and Dess, G.G. (1996), "Clarifying the entrepreneurial orientation construct and linking it to performance", Academy of Management Review, Vol. 21 No. 1, pp. 135-172. http://doi.org/ 10.2307/258632

Mahama, H. and Cheng, M.M. (2013). "The effect of managers' enabling perceptions on costing system use, psychological empowerment, and task performance", Behavioral Research in Accounting, Vol. 25 No. 1, pp. 89-114. https://doi.org/10.2308/bria-50333

Malmi, T. and Brown, D.A. (2008), "Management control systems as a package: opportunities, challenges and research directions", Management Accounting Research, Vol. 19 No. 4, pp. 287-300. http://doi.org/10.1016/j.mar.2008.09.003

Marginson, D. (2009), "Value systems as a mechanism for organizational change", Journal of Accounting \& Organizational Change, Vol. 5 No. 1, pp. 7-34. http://doi.org/10.1108/18325910910932197

Martens, C.D.P., Lacerda, F.M., Belfort, A.C., Freitas, H.M.R.D. (2016), "Research on entrepreneurial orientation: current status and future agenda", International Journal of Entrepreneurial Behavior and Research, Vol. 22 No. 4, pp. 556-583. http://doi.org/10.1108/IJEBR-08-2015-0183

Matsuo, M., Matsuo, T. and Arai, K. (2021), "The influence of an interactive use of management control on individual performance: mediating roles of psychological empowerment and proactive behavior", Journal of Accounting \& Organizational Change, Vol. 17 No. 2, pp. 263-281. http://doi.org/10.1108/JAOC-06-2020-0079

Merchant, K.A. and Otley, D. (2020), "Beyond the systems versus package debate", Accounting, Organizations and Society, Vol. 86, pp.1-7, 101185. https://doi.org/10.1016/j.aos.2020.101185

Messersmith, J.G. and Wales, W.J. (2013), "Entrepreneurial orientation and performance in young firms: the role of human resource management", International Small Business Journal, Vol. 31 No. 2, pp. 115-136. http://doi.org/10.1177/0266242611416141

Migliori, S., Pittino, D., Consorti, A. and Lucianetti, L. (2019), "The relationship between entrepreneurial orientation, market orientation and performance in university spin-offs", International Entrepreneurship and Management Journal, Vol. 15 No. 3, pp. 793-814. http://doi.org/10.1007/s11365-017-0488-x

Milgrom, P. and Roberts, J. (1995), "Complementarities and fit strategy, structure, and organizational change in manufacturing", Journal of Accounting and Economics, Vol. 19 No. 2-3, pp. 179-208. https://doi.org/10.1016/0165-4101(94)00382-F

Miller, D. (1983), "The correlates of entrepreneurship in three types of firms", Management Science, Vol. 29 No. 7, pp. 770-791. http://doi.org/10.1287/mnsc.29.7.770

Miller, D. and Friesen, P.H. (1983), "Strategy-making and environment: the third link", Strategic Management Journal, Vol. 4 No. 3, pp. 221-235. https://doi.org/10.1002/smj.4250040304 
Nuhu, N.A., Baird, K. and Appuhami, R. (2019), "The impact of management control systems on organisational change and performance in the public sector: the role of organisational dynamic capabilities", Journal of Accounting \& Organizational Change, Vol. 15 No. 3, pp. 473-495. http://doi.org/10.1108/JAOC-08-2018-0084

O'Grady, W. and Akroyd, C. (2016). "The MCS package in a non-budgeting organisation: a case study of Mainfreight", Qualitative Research in Accounting \& Management, Vol. 13 No. 1, pp. 2-30. https://doi.org/10.1108/QRAM-09-2014-0056

Otley, D.T. (1980). "The contingency theory of management accounting: achievement and prognosis", Accounting, Organizations and Society, Vol. 5 No. 4, pp. 413-428 https://doi.org/10.1016/0361-3682(80)90040-9

Otley, D. (2016), "The contingency theory of management accounting and control: 1980 2014", Management Accounting Research, Vol. 31, pp. 45-62. http://doi.org/10.1016/j.mar.2016.02.001

Palmer, C., Niemand, T., Stöckmann, C., Kraus, S. and Kailer, N. (2019), “The interplay of entrepreneurial orientation and psychological traits in explaining firm performance", Journal of Business Research, Vol. 94, pp. 183-194. http://doi.org/10.1016/j.jbusres.2017.10.005

Pavlatos, O. (2021), "Drivers of management control systems in tourism start-ups firms", International Journal of Hospitality Management, Vol. 92, pp. 1-9, 102746. http://doi.org/10.1016/j.ijhm.2020.102746

Pavlatos, O. and Kostakis, H. (2021), "Budgeting in start-up companies: European surveybased evidence", Advances in Management Accounting, Vol. 33.

Phillips, R.G. (2002), "Technology business incubators: how effective as technology transfer mechanisms?", Technology in Society, Vol. 24 No. 3, pp. 299-316. http://doi.org/10.1016/S0160-791X(02)00010-6

Plonski, G.A. (2016), "Innovation habitats for technology startups", Brazil. P. H. Phan, S. A. Mian, and W. Lamine", Technology Entrepreneurship and Business Incubation: Theory, Practice, Lessons Learned, pp. 125-150.

Podsakoff, P.M., MacKenzie, S.B., Lee, J.Y., and Podsakoff, N.P. (2003), "Common method biases in behavioral research: a critical review of the literature and recommended remedies", Journal of Applied Psychology, Vol. 88 No. 5, pp. 879-903. http://doi.org/10.1037/00219010.88.5.879

Ragin, C.C. (2000), Fuzzy-set social science. University of Chicago Press, Chicago.

Ragin, C.C. (2008), Redesigning Social Inquiry: Fuzzy Sets and Beyond. University of Chicago Press, Chicago.

Rehman, S.U., Bhatti, A., Kraus, S. and Ferreira, J.J. (2020), "The role of environmental management control systems for ecological sustainability and sustainable performance", Management Decision. Ahead-of-print. http://doi.org/10.1108/MD-06-2020-0800

Rezania, D., Baker, R. and Burga, R. (2016), "Project control: an exploratory study of levers of control in the context of managing projects", Journal of Accounting \& Organizational Change, Vol. 12 No. 4, pp. 614-635. http://doi.org/10.1108/JAOC-10-2015-0084

Rikhardsson, P., Rohde, C., Christensen, L. and Batt, C.E. (2021), "Management controls and crisis: evidence from the banking sector", Accounting, Auditing \& Accountability Journal, Vol. 34 No. 4, pp. 757-785. https://doi.org/10.1108/AAAJ-01-2020-4400

Rigtering, J.C., Eggers, F., Kraus, S. and Chang, M.L. (2017), "Entrepreneurial orientation, strategic planning and firm performance: the impact of national cultures", European Journal of International Management, Vol. 11 No. 3, pp. 301-324.

http://doi.org/10.1504/EJIM.2017.083872 
Rihoux, B. and Ragin, C.C. (2008), Configurational Comparative Methods: Qualitative Comparative Analysis (QCA) and Related Techniques (v. 51). Sage Publications, Thousand Oaks, California.

Ringle, C.M., Wende, S. and Becker, J.M. (2015), "SmartPLS 3”, Boenningstedt: SmartPLS $\mathrm{GmbH}$.

Samagaio, A., Crespo, N.F. and Rodrigues, R. (2018), "Management control systems in hightech start-ups: an empirical investigation”, Journal of Business Research, Vol. 89, pp. 351360. http://doi.org/10.1016/j.jbusres.2017.12.028

Sarstedt, M., Hair Jr, J.F., Cheah, J.H., Becker, J.M. and Ringle, C.M. (2019), "How to specify, estimate, and validate higher-order constructs in PLS-SEM", Australasian Marketing Journal (AMJ), Vol. 27 No. 3, pp. 197-211. http://doi.org/10.1016/j.ausmj.2019.05.003

Scagnelli, S., Vasile, L. and Apostolov, M. (2019), "Survival drivers of post-incubated startups: The effect of academic governance," International Journal of Innovation Management, Vol. 23 No. 07, pp. 1-20, 1950062. http://doi.org/10.1142/S1363919619500622

Schachel, H., Lachmann, M., Endenich, C. and Breucker, O. (2021), "The importance of management control systems for startup funding - empirical evidence from external financiers", Journal of Accounting \& Organizational Change, Ahead-of-print. https://doi.org/10.1108/JAOC-07-2020-0089

Shirokova, G., Bogatyreva, K., Beliaeva, T. and Puffer, S. (2016), "Entrepreneurial orientation and firm performance in different environmental settings", Journal of Small Business and Enterprise Development, Vol. 23 No. 3, pp. 703-727. http://doi.org/10.1108/JSBED-092015-0132

Strauss, E.R., Nevries, P. and Weber, J. (2013), "The development of MCS packages-balancing constituents' demands", Journal of Accounting \& Organizational Change, Vol. 9 No. 2, pp. 155-187. http://doi.org/10.1108/18325911311325942

Vaznyte, E. and Andries, P. (2019), 'Entrepreneurial orientation and start-ups' external financing", Journal of Business Venturing, Vol. 34 No. 3, pp. 439-458. http://doi.org/10.1016/j.jbusvent.2019.01.006

Venkatesh, V., Brown, S.A. and Bala, H. (2013), "Bridging the qualitative-quantitative divide: guidelines for conducting mixed methods research in information systems", MIS Quarterly, Vol. 37 No. 1, pp. 21-54. http://doi.org/10.25300/MISQ/2013/37.1.02

Vick, T.E., Nagano, M.S. and Santos, F.C.A. (2013), "Identifying the information management process and knowledge creation in technology-based companies: a Brazilian comparative case study", Knowledge Management Research and Practice, Vol. 11 No. 3, pp. 278-287. http://doi.org/10.1057/kmrp.2012.8

Wales, W.J. (2016), "Entrepreneurial orientation: a review and synthesis of promising research directions”, International Small Business Journal, Vol. 34 No. 1, pp. 3-15. http://doi.org/10.1177/0266242615613840

Wales, W.J., Covin, J.G. and Monsen, E. (2020), "Entrepreneurial orientation: the necessity of a multilevel conceptualization", Strategic Entrepreneurship Journal, Vol. 14 No. 4, pp. 639-660. http://doi.org/10.1002/sej.1344

Wales, W., Gupta, V.K., Marino, L. and Shirokova, G. (2019), "Entrepreneurial orientation: international, global and cross-cultural research", International Small Business Journal, Vol. 37 No. 2, pp. 95-104. http://doi.org/10.1177/0266242618813423

Wales, W., Monsen, E. and McKelvie, A. (2011), "The organizational pervasiveness of entrepreneurial orientation", Entrepreneurship Theory and Practice, Vol. 35 No. 5, pp. 895923. http://doi.org/10.1111/j.1540-6520.2011.00451.x

Walsh, G.S. and Cunningham J.A. (2016), "Business failure and entrepreneurship: emergence, evolution and future research", Foundations and Trends ${ }^{\circledR}$ in Entrepreneurship, Vol. 12 No. 3, pp. 163-285. http://doi.org/10.1561/0300000063 
Appendix A. Survey questionnaire

\begin{tabular}{lc}
\hline Construct/ Item & Loadin \\
\hline Entrepreneurial orientation & \\
How intense is your search for entrepreneurial features in your organization? & \\
Innovativeness (CR= 0.836; AVE= 0.630) & 0.761 \\
Investment in research and development (R\&D) & 0.868 \\
Introduction of new products/services in the last 3 years & 0.747 \\
Search for different ways to perform actions and solve problems & \\
Risk-taking (CR= 0.940; AVE= 0.886) & 0.953 \\
Performance in high-risk projects & 0.930 \\
Put yourself at risk to explore opportunities & $\mathrm{a}$ \\
Making financial loans & \\
Proactiveness (CR= 0.818; AVE= 0.602) & 0.817 \\
Pioneering in the implementation of products/services/technologies & 0.822 \\
Initiatives that cause competitive reactions & 0.680 \\
Constant monitoring of customer needs &
\end{tabular}

\section{Management control system package}

How intensively do you perceive your organization's control characteristics?

Cultural control $(\mathrm{CR}=0.865 ; \mathrm{AVE}=0.682)$

The organization's beliefs are highlighted

The organization's values, mission, and vision are emphasized to subordinates

Organizational symbols demonstrate the prevailing cultural aspects of the organization

Planning $(\mathrm{CR}=0.864 ; \mathrm{AVE}=0.560)$

In the short-term planning, the objectives of the functional areas are defined

In short-term planning, the objectives of the functional areas are passed on to employees

Long-term planning allows for the congruence of standards and goals, aligning

objectives in all functional areas

In the long-term planning, the activities of each subordinate are controlled

In long-term planning, the activities of all sectors of the organization are controlled

Cybernetic control $(\mathrm{CR}=0.887$; $\mathrm{AVE}=0.613)$

Performance measurements are used to quantify employees' behavior

Performance standards or goals are used in the organization

Feedback processes are adopted by comparing the achieved results to a previously

established standard

Analysis of variations due to feedback is performed

Subordinates are encouraged to increase their performance by awarding a reward

Rewards and compensation $(\mathrm{CR}=0.894 ; \mathrm{AVE}=0.738)$

There are ways to measurement on how much employees are focused on the activities

they perform 
There are ways measurements about the time spent by employees conducting some activities

There are ways measurements about the number of individuals involved in the pursuit of organizational goals

Administrative control $(\mathrm{CR}=0.847 ; \mathrm{AVE}=0.528)$

Performance is always monitored in the company, and employees are obliged to stand for their behavior

Behavior monitoring is used, employees are required to account for their behavior

Through an organization chart within the organizational structure, the allocation of subordinates is identified

There are processes in the company to specify how tasks or behaviors should be performed

The specification processes about how tasks or behaviors should be performed are adopted and passed on to subordinates

Performance $(\mathrm{CR}=0.881 ; \mathrm{AVE}=0.650)$

How intense do you perceive performance features in the past 3 years in your organization?

More competitive

Is growing faster

More profitable

More innovative

0.711

$\mathrm{a}=$ Item excluded to fit the model. 